\title{
Digital Disruption in the COVID-19 Era: The Impact on Learning and Students' Ability to Cope with Study in an Unknown World
}

\author{
Trixie James, Gabriela Toth, Melissa Tomlins, Brijesh Kumar and Kerry Bond \\ CQUniversity, Australia
}

\begin{abstract}
The COVID-19 pandemic will forever be known as a disruptive dilemma that impacted many industries in Australia. For the university sector, sudden lockdown and social distancing rules resulted in an acceleration in the provision of learning and teaching via online platforms, creating new challenges for students and educators. This project explored the ways in which an enabling course supported students through the forced transition from face-to-face classes to online learning due to the COVID-19 restrictions, and the students' ability to adjust to the disruption caused by the pandemic. This unexpected change provided the opportunity to explore how enabling students perceived this experience and the effect it had on their ability to complete their units of study. This paper presents findings on the impact that the abrupt transition to online learning had on the students' educational experience and on their psychological and emotional wellbeing. It was found that most students experienced increased stress due to the changes in household dynamics, responsibilities and a different learning context, yet many reported improved study and technological skills, as well as an improved awareness of their ability to cope with change.
\end{abstract}

Keywords: COVID-19; enabling; adult learners; disruption; online learning.

\section{Contextualisation}

In March 2020, much of Australia was put into lockdown as a result of the Australian Government's priority to contain the spread of the COVID-19 virus (Department of Health, 2020). This had significant implications for businesses, organisations and all levels of education (Franchi, 2020). By the end of March 2020, most higher education institutions had ceased all faceto-face classes, forcing students and staff to transition to online study.

It has been suggested that higher education is on the cusp of a new normal, with online learning emerging to enable more equitable access to higher education (Barsotti, 2020; D’Orville, 2020). Jonsson (cited in Barsotti, 2020) proposes that universities should take the present disruptions and the need to embrace technology as "an opportunity to open up education to people who learn differently" (p. 3). However, Barsotti warns that while this flexibility may work very well for many students, care needs to be taken to assist students who struggle with the online setting or feel isolated through its use. Ferreira (cited in Barsotti, 2020) suggests that "flexibility does not necessarily equate to better performance" (p. 1), indicating that without the structure of the classroom, greater pressure is placed on students' ability to manage their time. 
Maslen (2020) found that in Australia, more than one million students and 100,000 teaching and allied staff employed by 43 universities moved off-campus to study or work from home by late March 2020. This move accelerated the provision of online learning and teaching and created a "digital disruption", defined by Gartner Information Technology (2020) as "an effect that changes the fundamental expectations and behaviours in a culture, market, industry or process that is caused by... digital capabilities" (p. 1). Digital disruption saw many universities scramble to adjust to the sudden transition to fully online delivery in a context of widespread uncertainty and fear regarding the pandemic (Ippolito et al., 2020). People experienced further challenges in isolating at home, where normal daily activities were disrupted by homeschooling and other demands such as work and study (Maslen, 2020). The unexpected changes pervaded all aspects of people's lives. Unplanned digital education may have created new opportunities and skills for university students, but ongoing support in this educational environment is crucial for their success.

The research project reported in this paper considers the impact of the COVID-19 pandemic on students enrolled in an enabling course at a regional Australian university in Term 1 (March - June), 2020. The aim was to investigate how students experienced the transition to online learning during the first months of the COVID-19 pandemic by identifying the key factors that impacted the students' ability to study online and the aspects of the experience that they found most valuable. The study also explored whether the experience increased or hindered students' confidence to study online.

\section{Enabling Context}

Skills for Tertiary Education Preparatory Studies (STEPS) is an enabling course offered by CQUniversity that provides a pathway for students to gain entry to and succeed in higher education. As with other enabling courses, STEPS falls under the government's agenda to increase access to higher education for equity students (Edwards \& McMillan, 2015), including those who are first in family, refugees, Indigenous, mature aged, from low socio-economic or non-English speaking backgrounds, from regional or remote areas, or presenting with a disability (Australian Institute of Health and Welfare [AIHW], 2014; Drury \& Charles, 2016). James and Seary (2018) state that "the role of STEPS in creating a foundation for motivation and developing autonomous study habits is critical, as it may determine the students' willingness to commit to engaging more fully in undergraduate study" (p. 1). Students who enrol in an enabling pathway often do so due to past learning experiences that led to an inability to achieve the level of education required to transition successfully into undergraduate study (Klinger \& Tranter, 2009). These students may enter with uncertainty about their ability to handle the rigours of university, low levels of confidence, and/or limited academic skills such as academic writing, computing skills and mathematic skills (James, 2016; Klinger \&Tranter, 2009; Willans \& Seary, 2011). Crawford's (2021) recent research into rural and regional pre-tertiary students' experiences of transitioning to online study proposed that the fear and uncertainty triggered by the pandemic, alongside the disruption caused by the abrupt transition to online learning, was often exacerbated by low technological skill levels which created a disorienting experience for many students. These students, entering via an enabling program, not only need to improve their academic skills, but also require support for their emotional wellbeing (McConachie et al., 2008; Willans \& Seary, 2011). Seary and Willans (2020) suggest that a highly supportive environment with genuine, caring educators helps build strong relationships that enable students to feel confident in their enabling journey.

\section{Mode of Study}

In the STEPS course, a mixed mode of study was already on offer when the pandemic struck. STEPS students are able to enrol as online or internal (on-campus) students. Those who opt to study internally often also complete some units (subjects) online. As online delivery was already in place when the pandemic unfolded, the cohort enrolled as online students and the staff involved were not affected by the changes caused by the universities' shift to online delivery. However, internal educators had to rapidly develop or adapt content and adjust their pedagogy as they shifted previously face-to-face teaching to the online environment.

\section{Literature Review}

There are many studies about the value and effectiveness of online learning with varying findings. Stone (2017) found that both students and staff have similar views on what is required to keep students engaged and motivated with their studies. It is argued that educators should embrace digital communication advances and enact curriculum through educationally engaging digital platforms rather than trying to replicate face-to-face learning experiences at a distance (Stone, 2017). The design and 
development of quality resources for higher level engagement of online students requires time; however, the unexpected change brought by COVID-19 meant content had to be presented via an online platform at short notice and to the best ability of the educator (Stone \& Crawford, 2020).

\section{COVID-19 Fear and Student Wellbeing}

The COVID-19 pandemic created an environment of generalised fear. Fear is an adaptive emotion as it mobilises energy to deal with potential threats; however, when fear is not calibrated to the actual threat, it can be maladaptive (Mertens et al., 2020). This can lead to a range of psychological consequences (Liu et al., 2020), including anxiety, depression, substance abuse, and behavioural changes. Zhai and Du (2020) suggest that the closure of campuses and cessation of face-to-face classes could potentially increase mental health issues substantially. As many STEPS students are emotionally vulnerable (James \& Walters, 2020), it is possible that fear caused by the uncertainty surrounding the pandemic may exacerbate mental health problems. In addition, a recent study by Crawford (2021) found that studying online can be an isolating experience, which might be a trigger for higher levels of attrition for enabling students who are used to face-to-face teaching and support.

\section{Attrition in Online Education}

Attrition has been identified as a significant problem associated with online education. Tower et al. (2015) suggest that 50-70 per cent of students enrolled in online courses will withdraw. Enabling courses in Australia report an average of 50 per cent attrition, which is sometimes attributed to their open access policy (Hodges et al., 2013) or to the characteristics of this particular cohort, including low academic confidence (Atherton, 2015), inadequate technological skills or poor access to technology (Sturgess et al., 2016). However, prior to the pandemic, the STEPS attrition rate was 30 per cent, possibly because the personalised enrolment process and regular monitoring and support practices increase the chance for STEPS students to persist and complete their studies (Mann \& Salem, 2017).

\section{Methodology}

The key theory that underpins the current research is Transformative Learning Theory as introduced by Mezirow (1975). The transformative paradigm focuses on the lives and experiences of marginalised groups, which is core to the cohort of students who enter university via an enabling course (Seary \& Willans, 2020; Willans, 2010; Willans \& Seary, 2007). Mezirow (1997) describes transformative learning as adults having acquired a body of experiences which they can use as frames of reference that define their world. With the COVID-19 pandemic, students faced a disorienting dilemma (Cranton, 2006) that required them to question beliefs, personal assumptions or expectations, and look at the world through a new lens. A vital element of transformative learning is the ability to liberate students from restrictive influences and to free their ability to learn (Willans \& Seary, 2007). In this way, students come to appreciate their background and the knowledge they bring to the classroom, and then open themselves to a new world of critical knowledge, thus transforming their worldview (McConachie et al., 2008). This paper proposes that as these enabling students negotiate the COVID-19 dilemma, their perspective and belief in self may change as they develop their self-efficacy and achieve a higher level of psychological resilience.

\section{Methods}

This project used a mixed methodology approach whereby both quantitative and qualitative data were collected. Data on the participants' educational experience during COVID-19 was collected in a survey using a range of question types which provided both quantitative and qualitative responses. The survey was sent out at the completion of the term and asked students to reflect on their experience during Term 1, 2020. Additionally, in order to investigate the impact of Emergency Remote Teaching on attrition, data was extracted from the STEPS database and completion rates were analysed over a three-year period. To analyse the qualitative data from the survey, Braun and Clarke's (2006) Thematic Analysis was used to identify repeated patterns, or themes, in participant responses. Using this framework, researchers moved from a very broad lens for the creation of initial codes, to finding, reviewing and narrowing themes within the data. Analysis of the quantitative data were undertaken through Qualtrics, Excel and NVIVO. Descriptive statistics were used to present the data from the quantitative element of the survey. Ethical clearance was sought and approved by the Human Research Ethics Committee at CQUniversity [ID 0000022503]. 


\section{Participants}

An invitation to participate in this research was sent to all STEPS students enrolled in Term 1, 2020. Participation was optional and anonymous, protecting against actual or perceived coercion to participate. Participants were assembled through convenience sampling from the CQUniversity STEPS cohort of Term 1 2020, when COVID-19 restrictions began. An email was sent to 1303 students enrolled in both internal and online modes. Of these, 11 emails were returned as invalid addresses. A total of 156 of the 1292 students invited to do so completed the survey, which was a 12 per cent response rate.

\section{Demographics}

Of the 156 respondents:

- 36 per cent $(n=57)$ were $18-25$ years old;

- 39 per cent $(n=61)$ were $26-40$;

- 22 per cent $(n=34)$ were 41-55; and

- 3 per cent $(n=4)$ were 56 years or older.

Typically, STEPS enrols approximately 30 per cent male and 70 per cent female students. The sample broadly replicated this gender split, with 20 per cent male participants and 80 per cent female participants. Of the 156 students responding to the survey, at the beginning of Term 1:

- 51 per cent $(n=79)$ were online students;

- 40 per cent $(n=63)$ were on-campus (internal) students; and

- 9 per cent $(n=14)$ were enrolled in both online and on-campus units.

In terms of age, approximately 75 per cent of the total participants were aged 18-40 years old. The highest represented age group for the online participants were the 26-40 year-old age group and for the on-campus students, the 18-25-year-old age group.

\section{Limitations}

Invitations to participate were sent at the end of Term 1, 2020, so only students enrolled in that term responded to this survey. Students who had withdrawn were invited to participate; however, ongoing students formed the majority of respondents. This project also used self-reporting, which tends to be subjective as students' recollections can change over time; however, the survey questions allowed for a broad response to capture the essence of their experiences.

\section{Findings}

\section{Quantitative Findings}

Students were asked to reflect on their initial reaction to the COVID-19 pandemic. Approximately 65 per cent of the 156 students initially indicated they were "concerned," "very concerned," or "frightened" about the impacts of COVID-19. Eighteen per cent felt "sceptical" and 6 per cent "indifferent" about the pandemic. These results reflect a high level of uncertainty through this time. Mode of study had little influence on this initial perception; however, age was a factor in students' responses whereby the youngest group (18-25yo) showed the greatest concern, and the oldest group (56+yo) showed the least concern.

Students enrolled in face-to-face classes reported a lack of confidence in their ability to transition to online study with almost 50 per cent reporting that they were "not confident" and fewer than 10 per cent feeling "very confident" (see Figure 1). 


\section{Figure 1}

Confidence in the Transition to Online Mode

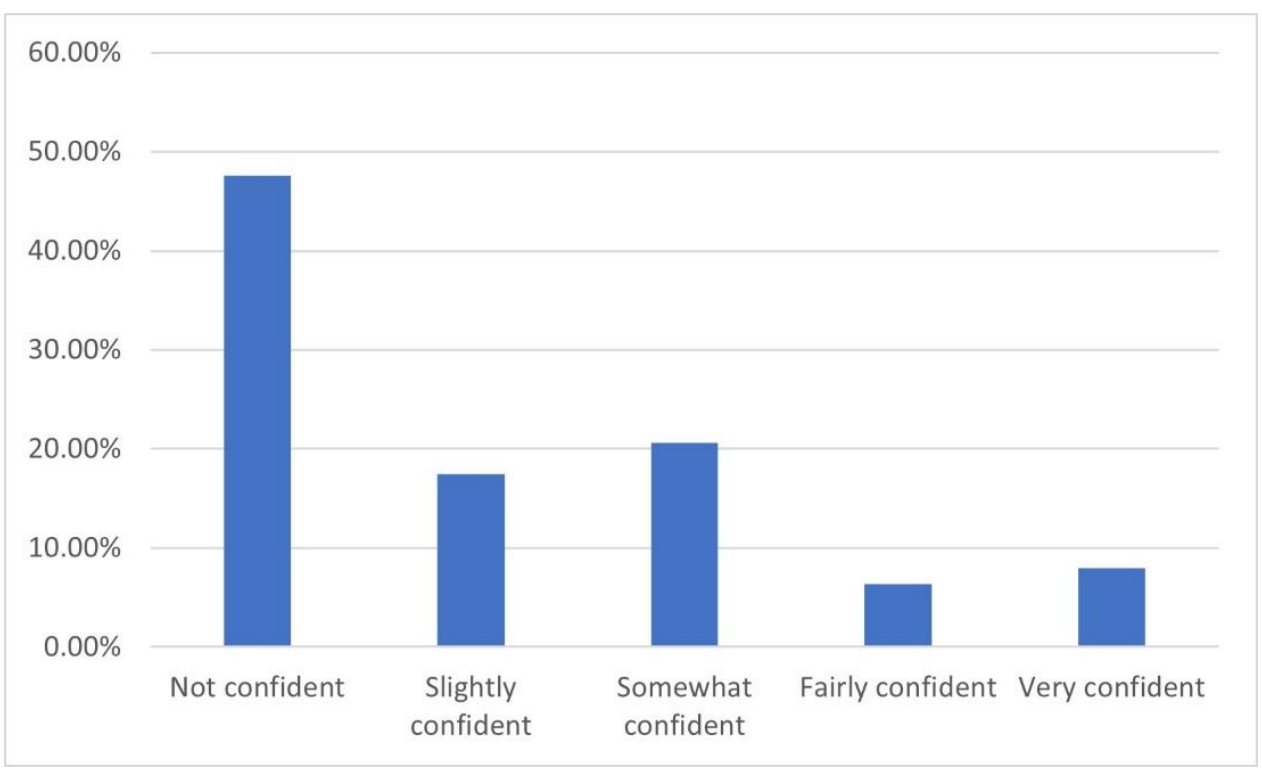

Students' responses suggested that despite the lack of confidence felt at the start of term, after experiencing online learning, approximately 60 per cent of the internal group reported that their online study skills had improved, while just under 35 per cent were not sure if there had been any change in their ability. This was comparable to the online students, who also reported improved skills at a similar rate (see Figure 2).

\section{Figure 2}

Perceptions that online study skills had improved

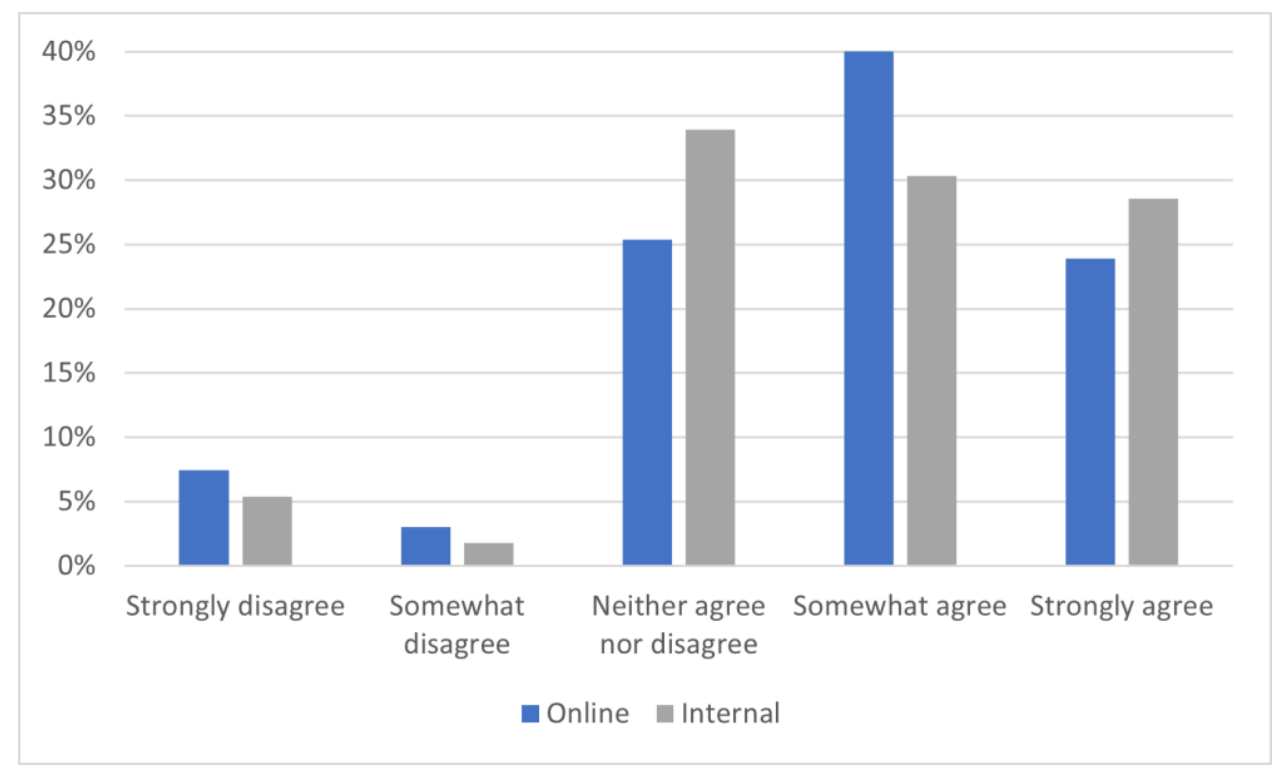

Lockdown brought changes for students in terms of time available and household arrangements. While approximately one in four students ( 27 per cent) reported that they had more time for study during lockdown, almost half ( 45 per cent) reported that they had less time. Commitments for online and on-campus students were similar, as both groups of students indicated that work, family, and homeschooling were the main competing commitments during Term 1. Finally, while most students reported having a suitable space to study during lockdown, 14 per cent said that their study space was not appropriate. 
It was expected that the number of students who failed units of study would increase in Term 1 due to the challenges imposed by COVID-19 and specifically, by the shift to online learning; however, data collected through the STEPS database indicated the failure rate was lower than in previous terms. As Figure 3 shows, the failure rate in Term 12020 was 25.9 per cent which is lower than both Term 12018 (27\%), and Term 12019 (31.5\%). The failure rate includes students who withdrew post census, those who did not complete the units, and those who failed to meet the required learning outcomes. The only variable which increased in Term 12020 was the number of applications for 'withdrawal without academic penalty' (WWAP) (shown as 'Withdrawn' in Figure 3), and this could be attributed to the challenges presented by COVID-19. The university was supportive of WWAPs, especially those related to issues resulting from the situation created by the pandemic, and of a more lenient approach to the consideration of extension requests. As can be seen in Figure 3, the success rate of STEPS students in Term 1 2020 is consistent with data for the same term in the previous two years. One suggestion for the success is that STEPS already had a robust online education system which was also available to internal students in Term 1, 2020. This capacity of lecturers to engage and support students may have contributed to student retention despite the challenges imposed by COVID-19. Future research will compare subsequent terms to find out whether there are variations to the retention and success rates.

Figure 3

Success and Failure Rates in STEPS Units (Term 1: 2018-2020)

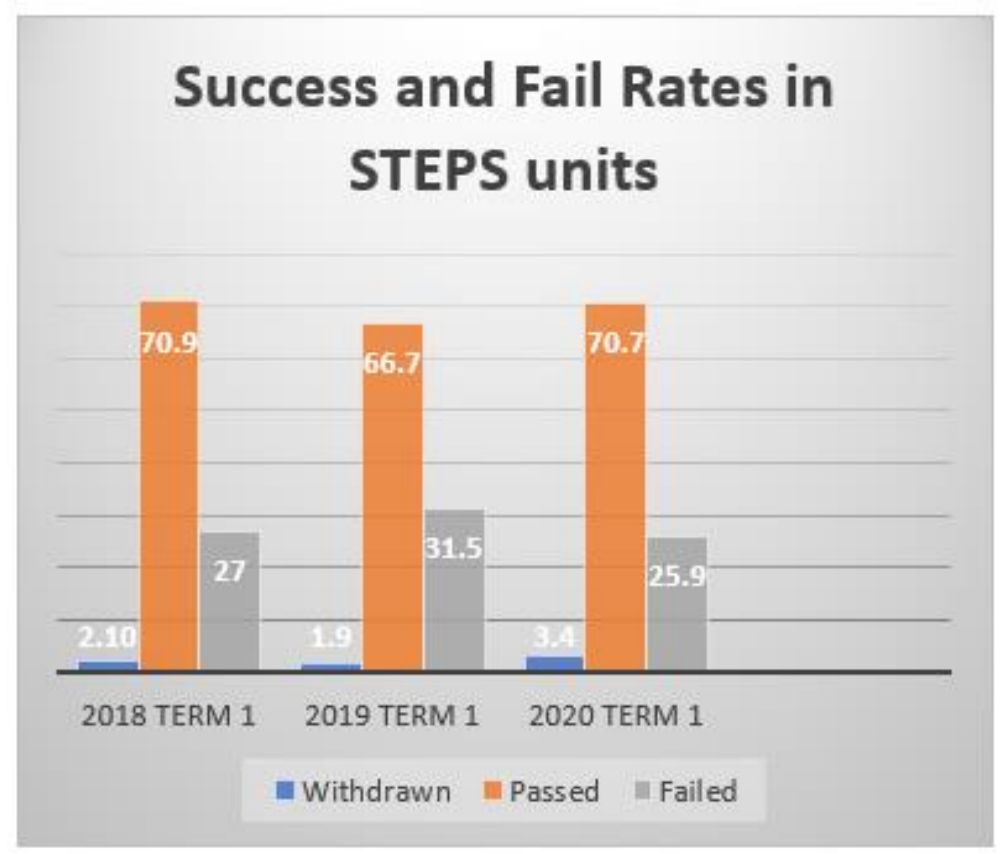

\section{Qualitative Findings}

\section{Challenges of the Transition to Online Study}

Internal and online students faced some similar challenges during the COVID-19 lockdown; however, for many in the internal cohort, online study was particularly daunting. The overarching theme evident from the student survey responses were the challenges caused by the disruption to students daily routines which were linked to the fear of the unknown through the pandemic. The key themes that emerged included the impacts of disruptions within their households, inability to make strong connections with peers and the upheaval of changing work patterns.

\section{Changing Households}

Homeschooling was often cited as having a significant impact on students' study time. Parents found that their "childrenfree" time, previously allocated to STEPS studies, was now dedicated to homeschooling: "time set away for study was often 
eaten into by my apparent "availability" due to being at home." Some respondents found managing homeschooling, their own study, work responsibilities and household tasks "a difficult juggling act." One respondent expressed frustration at having to manage the demands of the situation:

\begin{abstract}
... the stress of having to try and organise my children so I could log into zoom and do my sessions uninterrupted and then find time to study along with doing my son's homeschooling zoom sessions and helping him with all of his tasks and ensure he was doing everything his teachers set out for him, let's just say I'm glad that's over.
\end{abstract}

Having all household members at home at the same time also placed pressure on study space. Although there is no data about household numbers pre-COVID, during lockdown, more than 40 per cent of students had three to four people in their homes, 25 per cent had one or two, with another 25 per cent stating they had five or six in their household. Some students shared their study space with other household members: "I had set up my own study area prior to COVID-19. I did, however, have to share this space with a high school-aged son." For others, studying in a space which was normally used for other purposes created difficulties: "I spread out over the dining table! great amount of space for study, not so good for eating!" For some, the increased number of people at home created noise and other distractions: "It is a good-sized space but is hard to concentrate with other members of the household around." Unsuitable study spaces also exacerbated the difficulties of studying at home: "I studied in a small bedroom with no desk, and a lot of distractions, TV, phone etc." Others commented on the lack of separation between their roles, saying: "it was made harder by having to work at home as well as study at home." Meeting the demands of online studies was most challenging for households where home-schooled children and STEPS students with parental responsibilities had to share one laptop or had an unstable internet connection due to living in a remote area or not having a service which adequately supported multiple concurrent household users. Health issues, the inability to be close to relatives and fear about the pandemic was quite overwhelming for one respondent:

\footnotetext{
... it was everything combined... my son remote learning \& him being anxious, me struggling on my own with my own anxiety and tendency to become obsessive compulsive when stressed, then my grandmother all alone way out west in a nursing home, going into palliative care, and the confusion around how to see her due to the pandemic...
}

Factors such as pressure on time and space, changes in routines, and fear of the future resulting from the pandemic combined to create a stressful homelife for many of the students.

\title{
Relationships with Peers
}

Another impact of the lockdown for some respondents was the inability to build collegial relationships. Internal students who had experienced face-to-face learning felt they had lost contact with peers. One student summed up the sentiments of many respondents:

\begin{abstract}
The hardest aspect of online study is that there is absolutely no student-to-student interaction. Internal students have a chat after class, sit together after class, and build friendships. Since moving to an online study, I feel as though I am the only student in my class, it makes me feel isolated from a normal learning environment. For this reason, all the fun has been taken out of university.
\end{abstract}

Many respondents felt disconnected from peers and lecturers and their studies suffered as a result: "The insights gained during class discussions were invaluable, yet when we went online, only a handful of students seemed to be attending Zoom classes and discussion was minimal."

Technological issues further disrupted students' connection with others. For internal students, face-to-face classes were replaced by Zoom lessons, but some students were unable to log in as "the system was overloaded," whilst others were struggling to "understand how to use the technology properly" because "my devices weren't working properly making it difficult to study." Combined, the lack of direct contact had a significant impact for some students who felt that their educational experience was diminished by the forced online mode and further disrupted by the issues at home and with technology.

\section{Changing Work Patterns}

A further upheaval to routine was the sudden change to students' work arrangements. This was disruptive for many students and affected their capacity to engage with their studies. Many students who were essential workers experienced an increase in their number of work hours: "I worked as a medical receptionist, work demands increased... and I changed from working minimal days/hours to working $8-10 \mathrm{hr}$ shifts daily. I had to use lunch breaks to attend lectures.” For some, a reduction in work 
hours took a heavy toll. Several workers commented on the anxiety and stress derived from this change: "The stress of how I was going to provide for my family kept me awake at night for weeks." General uncertainty about continuing employment was also unsettling: "I was never sure if my hours would be cut or if I might be stood down." While the increase in work hours made finding time to study difficult, loss of work hours or job uncertainty created financial pressure. Thus, changes in work patterns constituted a further factor to which students had to adjust.

\section{Positive Aspects of the Transition to Online Study}

This study also set out to investigate what aspects of online learning students found most beneficial or enjoyable. The key themes that emerged were that many students appreciated the flexibility and convenience of online study, valued their lecturers' support, and observed improvements in the development of their skills and/or resilience.

\section{Convenience, Comfort, and Flexibility}

For some students, study offered a distraction, with a medical employee sharing that "coming to class was a break," and another reporting that "although being redundant for four weeks was initially a stressful situation, I was able to stay focused on my health and mental wellbeing by staying busy with study." The job losses impacted on students but created an "unplanned convenience" by allowing more time for study, as reflected by one student who commented: "My workplace was closed down for 8 weeks, so it gave me more time with one unit that I was struggling with." Campus closures and the cancellation of sporting and other activities offered an increased availability of study time. Internal students also highlighted the time and cost saving benefits of not having to commute to the campus: "It was so much easier not having to drive to campus for classes and to be able to do many things around class time."

The comfort and convenience afforded by home-based studying featured significantly as reasons for enjoyment. The home context enabled students to wear comfortable clothing, set up their study space in a house area of their choice and have food and other essentials within easy reach. While many responses pointed out numerous distractions that impacted on the students' capacity to focus, some students indicated that the absence of classroom chatter created an environment more conducive to study. For other students, however, integrating virtual classes into their routines required a conscious effort to establish clear boundaries between home and university "in the home," with some responses reporting strategies such as dressing appropriately to attend Zoom classes or "making sure I set up my desk and turned on the computer as soon as I got up so I knew I had uni."

The flexibility of online learning was identified as offering a number of advantages, as reflected by comments such as "doing it when I can," "having freedom of schedule," "working at my own pace," and "being able to attend lectures anywhere." For some students, the ability to combine study demands with household tasks or family commitments was a newfound convenience: "I enjoyed being able to attend class and still pick up my daughter from school even though class was at the same time. I was simply able to join class from my mobile phone."

The perceived benefits associated with the flexibility of online learning motivated a few internal students to continue their learning online, with one student saying: "I loved the independence that came from studying at home, and that's why I decided to change to external study." For some students, this changed preference resulted not only from the advantages offered by a more flexible mode of studying, but also from a learning experience they regarded as positive: "After easing into online learning, I really enjoyed studying online. I am now considering undertaking my undergraduate course as an external student. It suited my family commitments well." For a couple of students with anxiety issues, online study enabled a learning experience within their comfort zone:

I felt like online learning has better suited me because I am a very anxious person and was a lot more comfortable being in my own environment and by myself. I also struggle with insomnia and quite often missed day classes on campus because of this, working online allowed me to do my work whenever suited me best.

\section{Personal Development and Resilience}

Other positive themes that emerged from the transition to online learning were the development of new skills, a sense of achievement and an awareness of increased resilience.

Many students mentioned they had acquired important independent learning skills, while others acknowledged an improvement of their technological skills, including the use of online platforms such as Zoom and Moodle. Interestingly, although 43 per 
cent of the internal students reported being overwhelmed by the switch to online learning, 60 per cent of this cohort indicated that their online learning skills had improved towards the end of Term 1 and that they felt more confident about studying online. One student even foresaw the professional application of these new skills as "possible networking tools for my future career."

At the core of most definitions of resilience lies the concept of bouncing back from adverse situations. Gerson and Fernandez (2013), for instance, define resilience as the capacity to recover from stressful circumstances and to cope with challenges. A few students in this study enjoyed the challenge of extending themselves out of their "comfort zone," while others were proud of their capacity to keep studying despite adversity: "Being successful despite the adversity showed me I can cope in difficult situations." These examples of optimism, self-efficacy and psychological well-being point to the development of resilience (Johnson, 2008). Individual or group perseverance was a powerful motivator for some students, with one student feeling inspired by "watching others continue their studies and not giving up on their goals." This ability to maintain perspective has been recognised as one of the components of resilience (Winwood et al., 2013). Students' awareness of their endurance and often, improvement, as shown by a student for whom "finding out I'm not as dumb as I thought" was the most revealing aspect of the transition to online learning. This level of awareness signals the development of resilience and the students' ability to reflect on its impact.

\section{Perceptions of Teaching Quality and Support}

One finding was the students' appreciation of the effort made by the STEPS lecturers to deliver what they perceived as highquality approaches to teaching and support. Knowing everyone was in the same predicament helped students to handle the challenges and enjoy "being part of a team," where "... everyone helped each other. Lecturer and students alike were more considerate of each other and more willing to lend a hand." Responses also highlight a collegial relationship between lecturer and students: "I felt I had a good relationship with my lecturers and peers, as we were all in this together" and a heightened sense of connection: "I felt very engaged with my lecturers because as strange as it may sound, it felt very personal being connected with everyone." Moreover, many responses mentioned timetabled Zoom classes offered structure and helped students to build study networks and find support rather than being left to negotiate the online curriculum on their own.

Students valued their lecturers' availability, support, and their regular attempts to engage students who were inactive or struggling. Some words used to describe what they valued the most included: "supportive," "humour," "helpfulness," and "kindness." One comment illustrates the impact that lecturers' support had on the students' confidence: "The supportive, really, really, kind staff were a God-send - just all being "in it together" to get across the line during a challenging time probably gave my confidence a little boost by the end."

Lecturers' support was commended by most of the students with 83 per cent selecting 'agree' or 'strongly agree' to rate the statement that the lecturers provided quality support. The key difference from previous terms was that internal lecturers had to provide additional support to better assist students to transition to the online platforms. The positive impact that lecturers had on the students' experience was also noted by students who admitted to initially not enjoying studying online but actually finding it an enjoyable experience. One student shared: "I was motivated by my lecturers being engaged with my learning, and their encouragement for me to achieve good results." The STEPS course, as a whole, was very intentional in ensuring that student contact and communication was consistent throughout the entire term and that changes in delivery and updates on current situations were being reported quickly and regularly to all students.

\section{Discussion}

\section{Disruptive Elements}

The impact of governmental and executive decisions to close organisations and enforce lockdown to contain the spread of COVID-19, and of the pandemic itself, had far-reaching repercussions and disrupted many aspects of students' lives. Students contended with a myriad of disruptions, including changes to routines, invasion of personal space, technology issues, mental health issues, home-based work and homeschooling challenges, job losses and carer responsibilities. Research by Crawford (2021) identified that factors that caused disruption to normal routines also impacted on the students' ability to study online and were magnified by some issues such as access to technology and suitable study space, also identified in our study. Nevertheless, students found that some aspects of online study, such as Zoom sessions, were a welcome distraction from the isolation and frustrations caused by the lockdown. Students also valued their connections with peers and lecturers as well as a growing realisation of their own ability to cope with the change thrust upon them, thereby developing their self-efficacy and 
belief in their capacity to study online. As students adjusted to the 'new normal,' they also had to manage their fear, stress and/or anxiety. Khan et al. (2020) suggest that the stress and fear of infection of COVID-19 may generate moderate to major behavioural and psychological abnormalities. Support from educators and higher education institutions is important to assist enabling students, many of whom may already present with mental health issues, in their development of psychological resilience (Crawford et al., 2016). Heath et al. (2020) concur and state that organisations and individuals can develop mental, emotional, and interpersonal skills that foster adaptive coping responses, in turn contributing to both organisational and personal resilience. Emerging evidence suggests students can develop resilience even during times of uncertainty and fear and that resilience may have long-term benefits. However, this requires further research with consideration of recommending better support of students' mental health and wellbeing.

\section{Online Education}

In addition to the strategies employed by the university to ensure the transition to online teaching was as smooth as possible for both students and staff, such as providing technical support, ICT devices and constant communication, the individual departments had to undertake approaches to best support their student cohort. An intentional focus within STEPS was on how to support students most effectively through this transition and ensure that students were constantly updated on the changes and provided with explicit details about accessing the online classes.

While STEPS students who were enrolled online prior to the pandemic were already prepared to study in their home environment, most internal students initially found the changeover concerning. Many of these students expressed fears about using the digital platforms as their main source of content and interaction and they were concerned about missing the face-toface support of their lecturers. Croucher and Locke (2020) suggest that through this digital disruption, students' acceptance of online study will grow, even if it was not their initial preference for learning. This was supported by the present study, which showed some internal students shifting preference from on-campus to online learning.

\section{Conclusion}

The aim of this research was to better understand the experience of enabling students as they transitioned to online study during the first stages of the COVID-19 pandemic and contribute to new knowledge about enabling students' perceptions of this experience. This study showed that this transition was multi-dimensional, whereby students not only had competing commitments and constant disruptions, but they also had the fear of the unknown effects of the pandemic to contend with, as well as the common challenges faced by enabling students. This fear was reduced through the support arms provided by the STEPS lecturers. Yet, what was also evident was the personal skills development and increased psychological resilience experienced by many students. Once students felt at ease with the transition to online learning, most adapted and enjoyed the flexibility and convenience of studying at home. Whilst the digital disruption may have caused uncertainty and angst for both students and education providers, there is evidence to suggest that the online learning may become more widely used in higher education. To ensure enabling programs provide for the needs of their cohort, the online delivery of curriculum must include adequate support to assist students in the use of digital technologies, strategies to build and maintain peer and lecturer connections and focussed discussions to help develop their resilience capability. With this in mind, there is scope for followup research to further compare student satisfaction, retention, engagement and student well-being in this new COVID-19 era. Finally, recognising the importance of the educator in providing high quality teaching and in engaging students online is critical to ensure students learn effectively and that they feel connected and supported in their online learning communities. 


\section{References}

Atherton, M. (2015). Measuring confidence levels of male and female students in open access enabling courses. Issues in Educational Research, 25(2), 81-98.

Australian Institute of Health and Welfare. (2014, July 14). Towards a performance measurement framework for equity in higher education. Australian Government. https://www.aihw.gov.au/reports/indigenous-australians/equity-in-highereducation/contents/table-of-contents

Barsotti, S. (2020, September 14). Higher education was already ripe for disruption. Then, COVID-19 happened. Carnegie Mellon University. https://www.cmu.edu/news/stories/archives/2020/september/higher-education-covid-disruption.html

Braun, V., \& Clarke, V. (2006). Using thematic analysis in psychology. Qualitative Research in Psychology, 3(2), 77-101. https://doi.org/10.1191/1478088706qp063oa

Cranton, P. (2006). Understanding and promoting transformative learning: A guide for educators of adults (2 ${ }^{\text {nd }}$ Ed.). JosseyBass.

Crawford, N. (2021). Supporting student wellbeing during COVID-19: Tips from regional and remote Australia. National Centre for Student Equity in Higher Education (NCSEHE). https://www.ncsehe.edu.au/student-wellbeing-covid-19regional-remote-australia/

Crawford, N., Lisciandro, J., Jones, A., McCall, M., Bunn, R., Cameron, H., Westacott, M., \& Andersen, S. (2016, December 1-2). Models of support for student wellbeing in enabling programs: Comparisons, contrasts and commonalities at four Australian universities [paper presentation]. Foundations and Bridging Educators of New Zealand (FABENZ), Auckland. http://hdl.handle.net/20.500.11937/80712

Croucher, G., \& Locke, W. (2020, May). A post-coronavirus pandemic world: Some possible trends and their implications for Australian higher education [Discussion Paper]. University of Melbourne. https://melbournecshe.unimelb.edu.au/ data/assets/pdf_file/0010/3371941/a-post-coronavirus-world-for-higher-education final.pdf

Department of Health. (2020). Coronavirus (COVID-19) health alert. Australian Government. https://www.health.gov.au/news/health-alerts/novel-coronavirus-2019-ncov-health-alert

D’Orville, H. (2020). COVID-19 causes unprecedented educational disruption: Is there a road towards a new normal? Prospects, 49, 1-2, 11-55. https://doi.org/10.1007/s11125-020-09475-0

Drury, H., \& Charles, C. (2016). Overcoming disadvantage, achieving success: What helps. Journal of Academic Language \& Learning, 10(2), A48-A49.

Edwards, D., \& McMillan, J. (2015). Completing university in a growing sector: Is equity an issue? Australian Council for Educational Research. https://research.acer.edu.au/cgi/viewcontent.cgi?article=1045\&context=higher_education

Franchi, T. (2020). The impact of the Covid-19 pandemic on current anatomy education and future careers: A student's perspective. Anatomical Sciences Education, 113(3), 312-315. https://doi.org/10.1002/ase.1966

Gartner Information Technology. (2020). Digital disruption. https://www.gartner.com/en/informationtechnology/glossary/digital-disruption

Gerson, M. W., \& Fernandez, N. (2013). PATH: A program to build resilience and thriving in undergraduates. Journal of Applied Social Psychology 43, 2169-84. https://doi.org/10.1111/jasp.12168

Heath, C., Sommerfield, A., \& von Ungern-Sternberg, B. S. (2020). Resilience strategies to manage psychological distress among healthcare workers during the COVID-19 pandemic: A narrative review. Anaesthesia, 75(10), 1364-1371. https://doi.org/10.1111/anae.15180

Hodges, B., Bedford, T., Hartley, J., Klinger, C., Murray, N., O’Rourke, J., \& Schofield, N. (2013). Enabling retention: Processes and strategies for improving student retention in university-based enabling programs [Final Report 2013]. Office for Learning and Teaching. https://ltr.edu.au/vufind/Record/365262

Ippolito, G., Hui, D. S., Ntoumi, F., Maeurer, M., \& Zumla, A. (2020). Toning down the 2019-nCoV media hype - and restoring hope. The Lancet Respiratory Medicine, 8(3), 230-231. https://doi.org/10.1016/S2213-2600(20)30070-9

James, T. (2016). The juxtaposition of STEPS to the undergraduate arena: The lived experience of transitioning into undergraduate study. Australian Journal of Adult Learning, 56(2), 250-267.

James, T. \& Seary, K. (2018, November 29-30). What's so positive about positive psychology in an enabling program? [refereed paper]. Foundations and Bridging Educators of New Zealand (FABENZ), Wellington. http://fabenz.org.nz/proceedings-of-the-fabenz-conference-2018/

James, T., \& Walters, V. (2020). How positive is positive psychology in an enabling program? Investigating the transformative power of positive psychology for enabling students. Australian Journal of Adult Learning, 60(2), 170-189. https://www.ajal.net.au/downloads/how-positive-is-positive-psychology-in-an-enabling-program/

Johnson, B. (2008). Teacher-student relationships which promote resilience at school: A micro- level analysis of student's views. British Journal of Guidance \& Counselling 36(4), 385-98. https://doi.org/10.1080/03069880802364528

Khan, S., Siddique, R., Li, H., Ali, A., Shereen, M. A., Bashir, N., \& Zue, M. (2020). Impact of coronavirus outbreak on psychological health. Journal of Global Health, 10(1), 010331. https://doi.org/10.7189/jogh.10.010331 
Klinger, C. M., \& Tranter, D. (2009). Firm foundations for the future [paper presentation]. National Association of Enabling Educators of Australia, Toowoomba.

Liu, N., Zhang, F., Wei, C., Jia, Y., Shang, Z., Sun, L., Wu, L., Sun, Z., Zhou, Y., Wang, Y., Liu, W. (2020). Prevalence and predictors of PTSS during COVID-19 outbreak in China hardest-hit areas: Gender differences matter. Psychiatry Research, 287, 112921. https://doi.org/10.1016/j.psychres.2020.112921.

Mann, G., \& Salem, N. (2017, July 2-5). Every student counts: Individualised pathway support by an academic Access Coordinator through the STEPS enabling course [paper presentation]. STARS Conference, Adelaide, Australia https://unistars.org/papers/STARS2017/06D.pdf

Maslen, G. (2020, August 13). Coronavirus: Impacts of school and university lockdowns. University World News. https://www.universityworldnews.com/post.php?story=2020081313184272

McConachie, J., Seary, K., \& Simpson, J. (2008). Students' perceptions of a quality preparatory program at an Australian regional university: Success through changing worldviews. In J. McConachie, M. Singh, P.A. Danaher, F. Nouwens., \& G. Danaher (Eds.), Changing university learning and teaching: Engaging and mobilising leadership, quality and technology (pp. 87-106). Post Pressed.

Mertens, G., Gerritsen, L., Duijndam, S., Salemink, E., \& Engelhard, I. M. (2020). Fear of the coronavirus (COVID19): Predictors in an online study conducted in March 2020. Journal of Anxiety Disorders, 74, 102258. doi.org/10.1016/j.janxdis.2020.102258

Mezirow, J. (1975). Education for perspective transformation: Women's re-entry programs in community colleges. Columbia University.

Mezirow, J. (1997). Transformative learning: Theory to practice. New Directions for Adult \& Continuing Education, (74), 512. https://doi.org/10.1002/ace.7401

Seary, K., \& Willans, J. (2020). Pastoral care and the caring teacher: Value adding to enabling education. Student Success, 11(1), 12-21. https://doi.org/doi.org/10.5204/ssj.v11i1.1456

Stone, C. (2017). Opportunity through online learning: Improving student access, participation and success in higher education [Executive Summary]. The National Centre for Student Equity in Higher Education. https://www.ncsehe.edu.au/wp-content/uploads/2017/03/CathyStone_EXECUTIVE-SUMMARY-1.pdf

Stone, C., \& Crawford, N. (2020). Thinking about the students: Three essentials in the move on-line. Campus Morning Mail. https://campusmorningmail.com.au/news/thinking-about-the-students-three-essentials-in-the-move-online/?utm_campaign=website\&utm_source=sendgrid.com\&utm_medium=email

Sturgess, P., Cowling, M., \& Gray, M. (2016, February). Unpacking 'digital competency': Exploring the pre-existing skills of enabling education students [Conference paper]. Australasian Computer Science Week (ACSW) Multiconference, Canberra. https://doi.org/10.1145/2843043.2843349

Tower, M., Walker, R., Wilson, K., Watson, B., \& Tronoff, G. (2015). Engaging, supporting and retaining academic at-risk students in a Bachelor of Nursing: Setting risk markers, interventions and outcomes. The International Journal of the First Year in Higher Education, 6(1), 121-134. https://doi.org/10.5204/intifyhe.v6i1.251

Willans, J. (2010). Navigating personal change: Transforming perceptions of self as learner. Doctoral thesis, Rockhampton: CQUniversity.

Willans, J., \& Seary, K. (2007). I'm not stupid after all: Changing perceptions of self as a tool for transformation. Australian Journal of Adult Learning, 5(3), 434-452.

Willans, J., \& Seary, K. (2011). I feel like I'm being hit from all directions: Enduring the bombardment as a mature-age learner returning to formal learning. Australian Journal of Adult Learning, 51(1), 119.

Winwood, P. C., Colon, R., \& McEwen, K. (2013). A practical measure of workplace resilience: Developing the resilience at work scale. Journal of Occupational and Environmental Medicine, 55(10), 1205-1212. https://doi.org/10.1097/jom.0b013e3182a2a60a

Zhai, Y., \& Du, X. (2020). Addressing collegiate mental health amid COVID-19 pandemic. Psychiatry Research, 288, 113003. https://doi.org/10.1016/i.psychres.2020.113003

\section{Please cite this article as:}

James, T., Toth, G., Tomlins, M., Kumar B., \& Bond, K. (2021). Digital disruption in the COVID-19 era: The impact on learning and students' ability to cope with study in an unknown world. Student Success, 12(3), 84-95. https://doi.org/10.5204/ssj.1784 